\title{
Glyceryl trinitrate for the treatment of preterm labor
}

\author{
Şafak Çalışkan ${ }^{1}$, Mehmet Ali Narin², Faruk Suat Dede ${ }^{3}$, Raziye Narin ${ }^{4}$, Hülya Dede ${ }^{5}$, Ömer Kandemir ${ }^{3}$ \\ ${ }^{1}$ Clinic of Obstetrics and Gynecology, Nazilli State Hospital, Aydın, Turkey \\ ${ }^{2}$ Department of Obstetrics and Gynecology, Erzincan University Faculty of Medicine, Erzincan, Turkey \\ ${ }^{3}$ Clinic of Obstetrics and Gynecology, Etlik Zübeyde Hanım Training and Research Hospital Ankara, Turkey \\ ${ }^{4}$ Clinic of Obstetrics and Gynecology, Numune Training and Research Hospital, Adana, Turkey \\ ${ }^{5}$ Clinic of Obstetrics and Gynecology, Zekai Tahir Burak Training and Research Hospital, Ankara, Turkey
}

\section{Abstract}

Objective: This study was conducted to compare the tocolytic efficacy of glyceryltrinitrate (GTN) with that of magnesium sulfate (MgSO4) and to investigate serum nitric oxide metabolites before and after tocolysis.

Material and Methods: In total, 48 women between 27 and 34 weeks' gestation with threatened preterm labor and intact membranes were randomly allocated to receive either $\mathrm{GTN}$ or $\mathrm{MgSO}_{4}$ tocolysis. Main outcome measures included tocolytic efficacy and maternal side effect(s) of the tocolytic agent. Obstetric and neonatal outcomes as well as pretreatment and posttreatment nitric oxide (NO) metabolites were assessed. Results: Forty-one patients were included into the final analysis. Uterine contraction cessation times were $3.66 \pm 1.28$ and $6.83 \pm 3.47$ hours for GTN and MgSO4 groups, respectively. Similarly, maternal side effects were significantly lower in the GTN group than in the MgSO4 group, and no serious maternal side effects were recorded. Serum NO metabolite levels before treatment were significantly lower in the treatment groups than in the controls. Serum nitrite levels were significantly increased after tocolytic treatment both in $\mathrm{MgSO}_{4}$ and GTN groups.

Conclusion: GTN effectively delays preterm delivery and reduces neonatal morbidity and mortality with less maternal side effects and seems to be an effective and safe alternative to $\mathrm{MgSO}_{4}$. (J Turk Ger Gynecol Assoc 2015; 16: 174-8)

Keywords: Glyceryl trinitrate, nitric oxide, magnesium sulfate, tocolysis

Received: 28 January, 2015

Accepted: 24 March, 2015

Available Online Date: 14 July, 2015

\section{Introduction}

Preterm delivery is defined as birth before 37 completed weeks of gestation (1). Preterm birth complicates up to $10 \%$ of pregnancies and is the major cause of perinatal morbidity and mortality $(2,3)$. Despite advances in perinatal medicine, the incidence continues to increase $(4,5)$. The aim of tocolysis is to reduce neonatal morbidity and mortality by delaying birth, enabling corticosteroid administration or maternal transfer to a tertiary care center $(6,7)$. However, currently available tocolytics have poor efficacy and have not improved neonatal outcomes; furthermore, tocolytic agents have many maternal and fetal side effects, which generally limit their clinical usefulness (6). Human and animal studies suggest that nitric oxide (NO) is involved in the complex interplay of molecular activities, which regulate myometrial contractility (8-10). NO synthesis has been increased during pregnancy for maintaining a quiescent uterus and decreased during labor, thereby allowing uterine contractility to proceed to delivery (11-13). Some limited clinical studies have demonstrated that NO donors such as glyceryl trinitrate (GTN) can arrest preterm labor with less maternal/fetal side effects compared with other agents (14-17). However, contradictory data have been reported, stating that NO donors may have no myometrial effect or may decrease myometrial activity (18-20).
In most of these studies, GTN was compared with betamimetics; however, there has been no comparison of GTN with magnesium sulfate in terms of tocolytic activity and safety. The aim of the present study was to compare the efficacy and safety of GTN with those of magnesium sulfate $\left(\mathrm{MgSO}_{4}\right)$ for the treatment of preterm labor.

\section{Material and Methods}

This prospective, randomized, controlled study was conducted at the Obstetrics Department of a tertiary, referral, teaching, and research hospital. The study protocol was approved by the institutional research and local ethics committee.

\section{Study participants}

In total, 48 women from $27^{0 / 7}$ weeks to $34^{0 / 7}$ weeks of gestation who were in threatened preterm labor were randomly allocated to receive either GTN $(n=25)$ or $\mathrm{MgSO}_{4}(n=23)$ tocolysis, and the control group consisted of 25 pregnant women who were between the same gestational age and had no signs of threatened preterm labor.

Preterm labor was defined as the clinical diagnosis of at least two painful, regular uterine contractions every 10 minutes and evidence of cervical change (change in Bishop score or Bishop score $>6$ ). Inclusion criteria were single pregnancy 
with intact amniotic membrane, reassuring fetal heart rate (FHR) tracing, and no contraindication for tocolysis. Exclusion criteria included multiple pregnancy, nonreassuring FHR tracing, hypotension (blood pleasure $<80 / 50 \mathrm{mmHg}$ ), unexplained vaginal bleeding, placenta previa, preterm premature rupture of membranes, chorioamnionitis, cervical cerclage during present gestation, urinary system infection, maternal systemic disease, fetal growth restriction, and sensitivity or contraindication to nitrates or magnesium sulfate.

Eligible women were then approached to participate in the trial, and after final recruitment, the study protocol was explained to the patients and informed consents were obtained. The patients were randomized into two treatment groups according to software-generated random allocation sequence. The random allocation sequence was held by only one author during the entire trial period. The tocolytic drug was changed in four patients from the $\mathrm{MgSO}_{4}$ group and in three patients from GTN group, and these patients were excluded from the study in accordance with the study design (Figure 1). In conclusion, 19 patients in the $\mathrm{MgSO}_{4}$ group and 22 patients in GTN group were included in the final analysis. All the groups were matched with regard to maternal age, gestational age, and parity.

\section{Study design}

At the time of initial assessment, blood samples were collected for routine tests and serum nitrate and nitrite levels, following which maternal sedation with $10 \mathrm{mg}$ intramuscular (IM) diazepam (Diazem ${ }^{\circledR}$, Deva, Turkey) and hydration with $500 \mathrm{~mL}$ Ringer's lactate and with $500 \mathrm{~mL} 5 \%$ dextrose solution were performed. Betamethasone (Celestone Chronodose ${ }^{\circledR}$, Schering Plough, Turkey) was administered at $12 \mathrm{mg}$ IM every 24 hours for a total of two doses to all the patients for promoting fetal lung development. Patients could not be treated with sedation and hydration underwent $\mathrm{MgSO}_{4}$ or GTN treatment.

$\mathrm{MgSO}_{4}$ was performed; a loading dose of $6 \mathrm{~g}$ was given over 20 to 30 minutes and followed by an infusion of $3 \mathrm{~g} /$ hour. During tocolytic therapy, deep tendon reflexes, vital signs, fluid intake, and urinary output were measured hourly. Patients were followed with continuous fetal monitoring. Despite adequate blood levels of magnesium, if there was ongoing uterine activity, $\mathrm{MgSO}_{4}$ tocolysis was changed to GTN tocolysis and those patients were excluded from the study. $\mathrm{MgSO}_{4}$ treatment was continued for 12 hours after contractions had disappeared.

GTN patches $0.4 \mathrm{mg} / \mathrm{h}$ (Nitroderm ${ }^{\circledR} 10$ transdermal therapeutic system (TTS), Novartis Pharma, Turkey) were applied to the skin of the patients' abdomen. After 1 hour from the application of the patches, if there was ongoing uterine activity, a second patch was applied. At 24 hours after the initiation of treatment, the patches were removed. At 3 hours from application, if no changes were demonstrated in the uterine activity, GTN tocolysis was changed to $\mathrm{MgSO}_{4}$ tocolysis and those patients were excluded from the study. Maternal blood pressure was measured every 30 minutes for the first 3 hours and hourly thereafter after the placement of the patch. Side effects (e.g., hypotension, headache, dizziness, fatigue, tachycardia, facial flushing, itching) during the study period were recorded. Tocolytic treatment was stopped when patients experienced more severe adverse effects related to the tocolytic agent. Moderate headache was treated with paracetamol.

Bishop scores, total number of contractions in 10 minutes, the time interval between the initiation of the tocolytic treatment

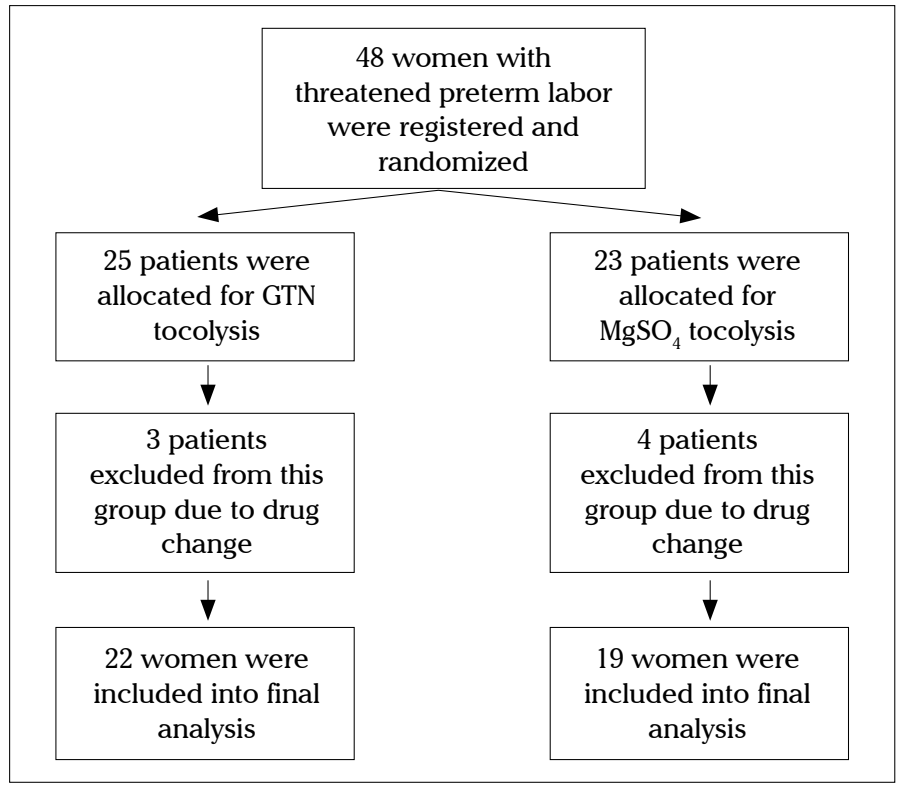

Figure 1. Patient randomization in the study

Table 1. Demographic characteristics of the study population

\begin{tabular}{|c|c|c|c|c|}
\hline & $\mathrm{MgSO}_{4}$ & GTN & Control & $\mathbf{p}$ \\
\hline Age $^{\mathscr{H}}$ & $25.53 \pm 4.94$ & $24.04 \pm 4.65$ & $25.09 \pm 3.44$ & 0.555 \\
\hline Gravida* & $2.0 \pm 1.71$ & $1.0 \pm 1.33$ & $1.0 \pm 1.53$ & 0.712 \\
\hline Parity* & $0.0 \pm 0.83$ & $0.0 \pm 1.23$ & $0.0 \pm 1.43$ & 0.889 \\
\hline $\begin{array}{l}\text { The number of } \\
\text { living children* }\end{array}$ & $0.0 \pm 0.83$ & $0.0 \pm 0.73$ & $0.0 \pm 0.53$ & 0.691 \\
\hline $\begin{array}{l}\text { Gestational age } \\
\text { at diagnosis } \\
(\text { weeks) }\end{array}$ & $31.4 \pm 3.0$ & $32 \pm 2.0$ & $31.6 \pm 3.0$ & 0.731 \\
\hline \multicolumn{5}{|c|}{$\begin{array}{l}{ }^{\mathscr{F}} \text { Presented as mean } \pm \mathrm{SD} \\
\text { * Presented as median } \pm \mathrm{SD} \\
\text { GTN: glyceryl trinitrate; } \mathrm{MgSO}_{4}: \text { magnesium sulfate }\end{array}$} \\
\hline
\end{tabular}

and resolving of uterine contractions, maternal side effect(s) of the tocolytic agent were compared between treatment groups. In addition, gestational age at delivery, mode of delivery, birth weights, Apgar scores, neonatal intensive care unit (NICU) admission, serum nitrate and nitrite levels, blood pressure, and pulse rate measurements were compared between all groups (treatment groups and controls).

\section{Statistical analysis}

All data collected were evaluated with Statistical Package for Social Sciences (SPSS, version 14, Chicago, Illinois, United States). For statistical analysis, Kruskal-Wallis, chi-square, and ANOVA tests were performed, and data were expressed as mean \pm SD or median \pm SD as appropriate. Statistical significance was defined as $\mathrm{p}<0.05$.

\section{Results}

Demographic characteristics of the patients were similar in all the groups (Table 1). While pretreatment Bishop scores and total number of uterine contractions in 10 minutes were not 
Table 2. Obstetric and perinatal data of patients

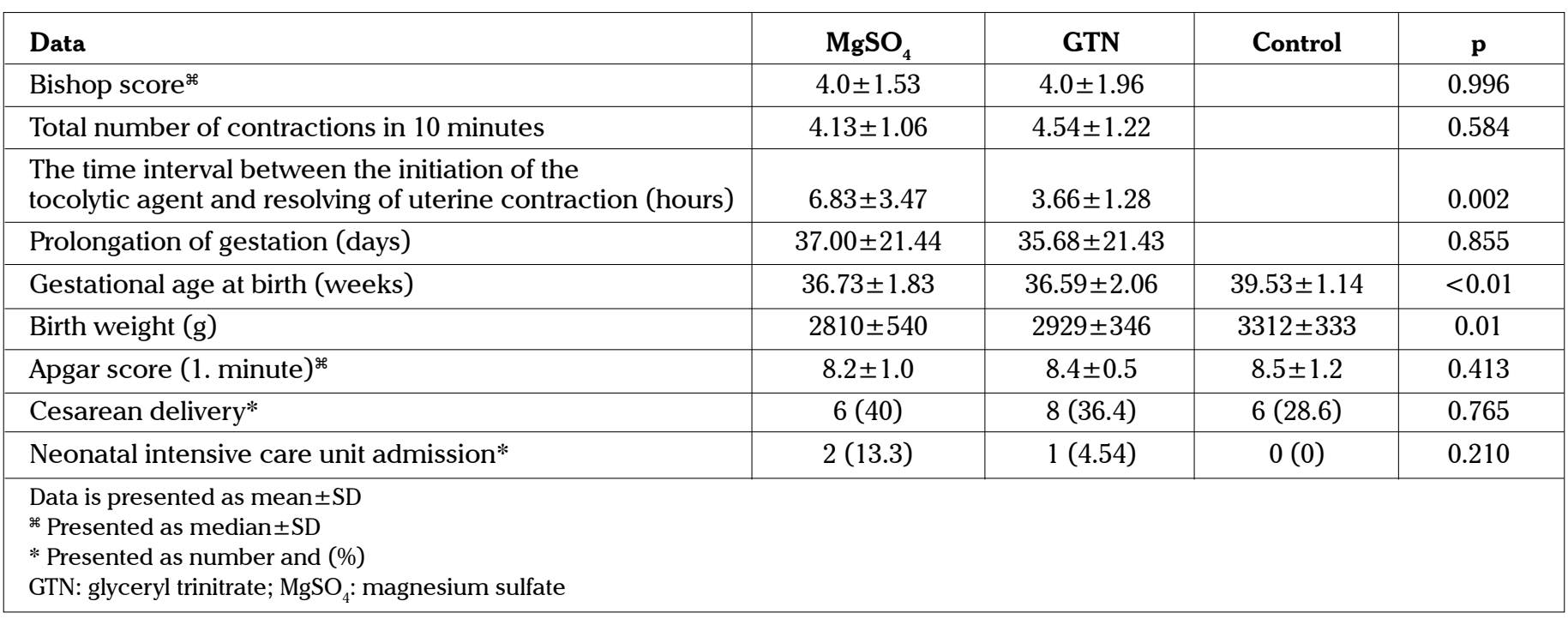

Table 3. Blood nitrate and nitrite levels in the treatment group before and after treatment

\begin{tabular}{|c|c|c|c|c|}
\hline & $\mathrm{MgSO}_{4}$ & GTN & Control & $\mathbf{p}$ \\
\hline Nitrate 1 (microM) & $21.32 \pm 5.15$ & $25.71 \pm 19.47$ & $32.10 \pm 9.94$ & 0.067 \\
\hline Nitrate 2 (microM) ${ }^{\mathrm{b}}$ & $17.77 \pm 3.88$ & $22.70 \pm 7.43$ & $32.10 \pm 9.94$ & $<0.01$ \\
\hline Nitrite 1 (microM)c & $8.65 \pm 0.57$ & $8.97 \pm 0.81$ & $11.82 \pm 1.21$ & $<0.01$ \\
\hline Nitrite $2(\text { microM })^{d}$ & $11.66 \pm 1.39$ & $11.20 \pm 1.35$ & $11.82 \pm 1.21$ & 0.259 \\
\hline $\begin{array}{l}\text { aNitrate 1: Pretreatment nitrate levels } \\
{ }^{b} \text { Nitrate 2: Nitrate levels after the treatment } \\
{ }^{c} \text { Nitrite 1: Pretreatment nitrite levels } \\
{ }^{d} \text { Nitrite } 2 \text { : Nitrite levels after the treatment } \\
\text { (microMol=microM) } \\
\text { GTN: glyceryl trinitrate; } \mathrm{MgSO}_{4} \text { : magnesium sulfate }\end{array}$ & & & & \\
\hline
\end{tabular}

significantly different between $\mathrm{MgSO}_{4}$ and GTN groups, the time interval between the initiation of the tocolytic agent and resolving of uterine contractions was significantly shorter in GTN group (3.66 \pm 1.28 hours) than in the $\mathrm{MgSO}_{4}$ group $(6.83 \pm 3.47$ hours). However, no significant difference was found between the treatment groups with regard to the overall prolongation of pregnancy, which is regarded as the determinant of success in the treatment of preterm delivery. This period was $37.00 \pm 21.44$ days for $\mathrm{MgSO}_{4}$ tocolysis and 35.68 \pm 21.43 days for GTN tocolysis (Table 2). Although there were no significant differences between $\mathrm{MgSO}_{4}$ and GTN groups in terms of the gestational age at delivery $(36.73 \pm 1.83$ and $36.59 \pm 2.06$, respectively) and birth weight ( $2810 \pm 540$ and $2929 \pm 346$, respectively), these parameters were significantly higher in the control group (Table 2). Apgar scores, cesarean delivery, and NICU admission rates were found to be similar between the treatment and control groups (Table 2).

Serum nitrate and nitrite levels before and after tocolytic treatment in the study and control groups are shown in Table 3. Serum nitrate and nitrite levels were significantly lower in the treatment groups than in the controls before tocolytic treatment. After tocolytic treatment, serum nitrate levels were found to be decreased in both $\mathrm{MgSO}_{4}$ and GTN groups; however, this decrease did not reach statistical significance. Although serum nitrite levels were significantly increased after tocolytic treatment in $\mathrm{MgSO}_{4}$ and GTN groups, no significant difference was found between the treatment and control groups in terms of serum nitrite levels after tocolytic therapy (Table 3). Blood pressure values after treatment were significantly lower in the treatment groups than in the control group; however, there was no statistically significant difference between $\mathrm{MgSO}_{4}$ and GTN groups with respect to decreasing blood pressures after treatment. Although the mean pulse rate was found to be significantly increased after treatment in the treatment groups, the increase in the pulse rate was greater in GTN group than in the $\mathrm{MgSO}_{4}$ group. Similarly, maternal side effects were significantly lower in the GTN group than in the $\mathrm{MgSO}_{4}$ group (Table 4). Flushing was the most frequent side effect in the $\mathrm{MgSO}_{4}$ group; however, it was not severe enough to require termination of treatment.

\section{Discussion}

The present study has demonstrated that GTN successfully stopped preterm uterine contractions in a shorter duration of time than $\mathrm{MgSO}_{4}$ before 34 weeks' gestation and seemed to be 
Table 4. Maternal adverse events recorded during the treatment

\begin{tabular}{|l|c|c|}
\hline Adverse event* & MgSO $_{4}$ & GTN \\
\hline Headache & $2(13.3 \%)$ & $3(13.6 \%)$ \\
\hline Palpitation & $1(6.6 \%)$ & $2(9.1 \%)$ \\
\hline Dizziness & $2(13.3 \%)$ & - \\
\hline Nausea & $1(6.6 \%)$ & - \\
\hline Flushing & $4(26.6 \%)$ & - \\
\hline Total & $7(66.4 \%)$ & $5(22.7 \%)$ \\
\hline $\begin{array}{l}\text { *Presented as number and percent } \\
\text { GTN: glyceryl trinitrate; } \text { MgSO }_{4}: \text { magnesium sulfate }\end{array}$
\end{tabular}

more effective than $\mathrm{MgSO}_{4}$ when patients had more frequent contractions and required emergency tocolysis. However, the overall gestation prolongation times were similar for both GTN and $\mathrm{MgSO}_{4}$, and this denotes that both the agents have similar tocolytic activity. Lees et al. (14) demonstrated that pregnancy was prolonged up to 34 days in 13 patients treated with $10 \mathrm{mg}$ GTN despite their relative small sample size. In another multicenter study, Lees et al. (19) compared the effect of ritodrine with that of GTN and demonstrated that the mean prolongation of gestation was 36.9 days for ritodrine and 35.8 days for GTN; however, this difference was not significant. These gestation prolongation times were consistent with our results; however, in a randomized, double-blind, placebo-controlled study, Smith et al. have found that GTN patches have prolonged pregnancy for 22 days (21). This difference may have resulted from different patient selection criteria.

$\mathrm{NO}$, a free radical synthesized by a family of enzymes known as NOS, is an important physiological regulator of uterine contractility (22). NO inhibits uterine contractility by various mechanisms, including the reduction of intracellular calcium levels via protein kinase $\mathrm{C}$, activation of calcium pumps, and suppression of the expression of gap junctions consisting of proteins called connexin $43(\mathrm{Cx} 43)$, resulting in the facilitation of action potential propagation from one cell to another (23-25). Endogenous metabolism of $\mathrm{NO}$ gives rise to plasma and urinary nitrite $\left(\mathrm{NO}_{2}\right)$ and nitrate $\left(\mathrm{NO}_{3}\right)$. The serum levels of the $\mathrm{NO}$ metabolites reflect $\mathrm{NO}$ activity in human. Nitrite is a better indicator than nitrate. Therefore, the measurement of metabolites of $\mathrm{NO}$, nitrite, and nitrate in plasma/urine/amniotic fluid/vaginal secretions could be used to evaluate NO activity in humans. The reduction of serum NO metabolites levels, particularly nitrite levels, in active spontaneous preterm labor and in the active phase of induced labor at term has been shown, and it is most likely to be an indicator of a downward regulation of $\mathrm{NO}$ production with the onset of labor (26). The results of our study have demonstrated that serum nitrate and nitrite levels before treatment were significantly lower in the treatment groups than in the controls and serum nitrite levels were significantly higher after tocolytic treatment. Similarly, higher serum nitrite levels have been shown in patients without labor than in those with preterm or term labor (26). It may suggest that the beneficial effect of $\mathrm{MgSO}_{4}$ and GTN on the treatment of preterm labor depends on the increase in serum NO metabolite levels.
The present study indicated significantly lower blood pressures and higher pulse rates in treatment groups. However, these findings have improved in a few hours of treatment and were not severe enough to require the termination of treatment. A randomized, double-blind, placebo trial including 74 infants born to transdermal nitroglycerin-treated mothers has indicated that transdermal nitroglycerin may reduce neonatal morbidity and mortality as a result of decreased risk of birth before 28 weeks but can cause significantly more maternal side effects (27). However, according to our results, maternal side effects were found to be significantly lower in the GTN group. It may arise from their relatively larger sample size $(n=74)$. Although there are several reports in the literature indicating a significant decrease in the blood pressure and increase in the pulse rate after GTN tocolysis, many reports have also indicated minor changes, which do not require any interventions, in the abovementioned vital signs (28-31).

In conclusion, in the light of our results, GTN seems to be safe, well-tolerated, and as effective as several commonly used labor-delaying medications. In addition, it has less side effects. Therefore, it may be an appropriate alternative for the treatment of preterm labor.

The limitations of our study were the small sample size and short-term follow-up period. Further trials are required to clarify this subject.

Ethics Committee Approval: Ethics committee approval was received for this study from the Local Institutional ethics committee of Ankara Etlik Zübeyde Hanım Training and Research Hospital.

Informed Consent: Written informed consent was obtained from patients who participated in this study.

Peer-review: Externallypeer-reviewed.

Author Contributions: Concept - SS.Ç., M.A.N.; Design - SS.Ç.; Supervision S.D., H.D.; Resource - S.C., M.A.N., R.N.; Materials - S.C.; Data Collection and/or Processing - SSC., M.A.N., R.N.; Analysis and/or Interpretation - S.C..; Literature Search - Sु.Ç., M.A.N.; Writing - Ş.Ç., M.A.N.; Critical Reviews - S.D., H.D., Ö.K.

Conflict of Interest: No conflict of interest was declared by the authors.

Financial Disclosure: The authors declared that this study has received no financial support.

\section{References}

1. Slattery MM, Morrison JJ. Preterm delivery. Lancet 2002; 360: 148997. [CrossRef]

2. Berkowitz GS, Papiernik E. Epidemiology of preterm birth. Epidemiol Rev 1993; 15: 414-43.

3. Petrou $\mathrm{S}$. The economic consequences of preterm birth during the first 10 years of life. BJOG 2005; 112 (Suppl 1): 10-5. [CrossRef]

4. Joseph KS, Kramer MS, Marcoux S, Ohlsson A, Wen SW, Allen A, Platt R. Determinants of preterm birth rates in Canada from 1981 through 1983 and from 1992 through 1994. N Engl J Med 1998; 339: 1434-9. [CrossRef]

5. Ananth CV, Joseph KS, Oyelese Y, Demissie K, Vintzileos AM. Trends in preterm birth and perinatal mortality among singletons: United states, 1989 through 2000. Obstet Gynecol 2005; 105: 1084-91. [CrossRef]

6. ACOG Committee on Practice Bulletins--Obstetrics. ACOG practice bulletin. Management of preterm labor. Number 43, May 2003. Int J Gynaecol Obstet 2003; 82: 127-35. [CrossRef] 
7. Smith GN. What are the realistic expectations of tocolytics? BJOG 2003; 110 (Suppl 20): 103-6. [CrossRef]

8. Sladek SM, Magness RR, Conrad KP. Nitric oxide and pregnancy. Am J Physiol 1997; 272 ( 2Pt 2): R441-63.

9. Yallampalli C, Dong YL, Gangula PR, Fang L. Role and regulation of nitric oxide in the uterus during pregnancy and parturition. J Soc Gynecol Investig 1998; 5: 58-67. [CrossRef]

10. Ledingham MA, Thomson AJ, Greer IA, Norman JE. Nitric oxide in parturition. BJOG 2000; 107: 581-93. [CrossRef]

11. Ali M, Buhimschi I, Chwalisz K, Garfield RE. Changes in expression of the nitric oxide synthase isoforms in rat uterus and cervix during pregnancy and parturition. Mol Hum Reprod 1997; 3: 995-1003. [CrossRef]

12. Farina M, Ribeiro ML, Franchi A. Nitric oxide synthases in pregnant rat uterus. Reproduction 2001; 121: 403-7. [CrossRef]

13. Buhimschi I, Yallampalli C, Dong YL, Garfield RE. Involvement of a nitric oxide-cyclic guanosine monophosphate pathway in control of human uterine contractility during pregnancy. Am J Obstet Gynecol 1995; 172: 1577-84. [CrossRef]

14. Lees C, Campbell S, Jauniaux E, Brown R, Ramsay B, Gibb D, et al. Arrest of preterm labour and prolongation of gestation with glyceryl trinitrate, a nitric oxide donor. Lancet 1994; 343: 1325-6. [CrossRef]

15. Rowlands S, Trudinger B, Visva-Lingam S. Treatment of preterm cervical dilatation with glyceryl trinitrate, a nitric oxide donor. Aust N Z J Obstet Gynaecol 1996; 36: 377-81. [CrossRef]

16. Schleussner E, Moller A, Gross W, Kahler C, Moller U, Richter $\mathrm{S}$, Seewald HJ. Maternal and fetal side effects of tocolysis using transdermal nitroglycerin or intravenous fenoterol combined with magnesium sulfate. Eur J Obstet Gynecol Reprod Biol 2003; 106: 14-9. [CrossRef]

17. Norman J. Nitric oxide and the myometrium. Pharmacol Ther 1996; 70: 91-100. [CrossRef]

18. Jones GD, Poston $\mathrm{L}$. The role of endogenous nitric oxide synthesis in contractility of term or preterm human myometrium. Br J Obstet Gynaecol 1997; 104: 241-5. [CrossRef]

19. Lees CC, Lojacono A, Thompson C, Danti L, Black RS, Tanzi P, et al. Glyceryl trinitrate and ritodrine in tocolysis: An international multicenter randomized study. Gtn preterm labour investigation group. Obstet Gynecol 1999; 94: 403-8. [CrossRef]

20. Bisits A, Madsen G, Knox M, Gill A, Smith R, Yeo G, et al. The randomized nitric oxide tocolysis trial (rnott) for the treatment of preterm labor. Am J Obstet Gynecol 2004; 191: 683-90. [CrossRef]

21. Smith GN, Walker MC, McGrath MJ. Randomised, double-blind, placebo controlled pilot study assessing nitroglycerin as a tocolytic. Br J Obstet Gynaecol 1999; 106: 736-9. [CrossRef]

22. Moncada S, Palmer RM, Higgs EA. Nitric oxide: Physiology, pathophysiology, and pharmacology. Pharmacol Rev 1991; 43: 109-42.

23. Rosselli M, Keller PJ, Dubey RK. Role of nitric oxide in the biology, physiology and pathophysiology of reproduction. Hum Reprod Update 1998; 4: 3-24. [CrossRef]

24. Chwalisz K, Garfield RE. Regulation of the uterus and cervix during pregnancy and labor. Role of progesterone and nitric oxide. Ann N Y Acad Sci 1997; 828: 238-53. [CrossRef]

25. Roh CR, Heo JH, Yang SH, Bae DS. Regulation of connexin 43 by nitric oxide in primary uterine myocytes from term pregnant women. Am J Obstet Gynecol 2002; 187: 434-40. [CrossRef]

26. Diejomaoh MF, Omu AE, Taher S, Al-Busiri N, Fatinikun T, Fernandes $\mathrm{S}$, Al-Othman S. Nitric oxide metabolites in preterm and induced labor. Gynecol Obstet Invest 2003; 56: 197-202. [CrossRef]

27. Smith GN, Walker MC, Ohlsson A, O'Brien K, Windrim R; Canadian Preterm Labour Nitroglycerin Trial Group. Randomized doubleblind placebo-controlled trial of transdermal nitroglycerin for preterm labor. Am J Obstet Gynecol 2007; 196: 37.e1-8. [CrossRef]

28. Buxton IL, Crow W, Mathew SO. Regulation of uterine contraction: Mechanisms in preterm labor. AACN Clin Issues 2000; 11: 271-82. [CrossRef]

29. Dong YL, Fang L, Gangula PR, Yallampalli C. Regulation of inducible nitric oxide synthase messenger ribonucleic acid expression in pregnant rat uterus. Biol Reprod 1998; 59: 933-40. [CrossRef]

30. Tiboni GM, Giampietro F. Inhibition of nitric oxide synthesis causes preterm delivery in the mouse. Hum Reprod 2000; 15: 1838-42. [CrossRef]

31. Leszczynska-Gorzelak B, Laskowska M, Marciniak B, Oleszczuk J. Nitric oxide for treatment of threatened preterm labor. Int $\mathrm{J}$ Gynaecol Obstet 2001; 73: 201-6. [CrossRef] 